\title{
DEVELOPMENT AND EVALUATION OF MONOLITHIC OSMOTIC TABLET OF KETOPROFEN: USING SOLID DISPERSION TECHNIQUE
}

\author{
S. KAUSHIK*, KAMLA PATHAK \\ Department of Pharmaceutics, Pharmacy College Safai, U. P. RIMS and R, Safai (District Etawah) 206130 Uttar Pradesh, India \\ Email: sk.mathura20@gmail.com
}

Received: 27 Feb 2016 Revised and Accepted: 050 oct 2016

\begin{abstract}
Objective: The aim of the present study was to develop and evaluate the monolithic osmotic tablet (MOT) composed of the solid dispersion of ketoprofen (KETO), a poorly water-soluble drug. Solid dispersion technique is generally used for immediate release, as this maximizes the amount of drug absorbed. Sustained release may be obtained by combining solid dispersion technique with MOT so as to increase the therapy efficacy and patient compliance.
\end{abstract}

Methods: Solid dispersion of KETO was prepared by using solvent melt method with polyethylene glycol (PEG) 6000, a hydrophilic carrier. The ratio of KETO to PEG 6000 were 1:1, 1:3 and 1:5 (\%w/w). These solid dispersions were characterized by differential scanning calorimetry (DSC), Thermogravimetric analysis (TGA) and powder X-ray diffraction (PXRD) to ascertain whether there were any physicochemical interactions between drug and carrier.

The tablet core was prepared by using Polyox N80 (a suspending agent), sodium chloride (an osmotic agent), a solid dispersion consisting of PEG 6000 and KETO followed by a coating of cellulose acetate to make the monolithic osmotic tablet.

Results: The results of DSC and PXRD indicated that the drug was in the amorphous state in solid dispersion when PEG 6000 was used as a carrier. The dissolution rate of the solid dispersion was much faster than those for the corresponding physical mixture and pure drug. The optimized MOT formulations were able to deliver KETO at the constant zero order release, above $95 \%$ in vitro, independent to environmental media and stirring rate. The release rate of KETO in the MOT is controlled by osmotic pressure, suspending agent and drug solubility in solid dispersion.

Conclusion: The monolithic osmotic tablet containing solid dispersion has great potential in the controlled delivery of ketoprofen, a water-insoluble drug.

Keywords: Ketoprofen, Monolithic osmotic tablet, Solid dispersion, Water insoluble

(C) 2016 The Authors. Published by Innovare Academic Sciences Pvt Ltd. This is an open access article under the CC BY license (http://creativecommons.org/licenses/by/4. 0/] DOI: http://dx.doi.org/10.22159/ijpps.2016v8i12.11437

\section{INTRODUCTION}

The bioavailability of poorly water-soluble drugs is well known to be limited and profoundly affected by the rate of absorption in the gastrointestinal tract (GIT). As the low solubility of drugs is one of the most important factors affecting the drug release process, many methods have been proposed to enhance the drug solubility. Among the several strategies available for improving drug bioavailability, solid dispersions (SDs) have been used extensively [1-6]. The SD technique produces a significant increase in surface area and surface wettability as well as solid state modification from crystalline to amorphous form. Hence, SD is widely used to increase the solubility, dissolution rate, and bioavailability of water-insoluble drugs [7-8].

The monolithic osmotic tablet (MOT) system, which is composed of a monolithic tablet coated with cellulose acetate (CA) membrane drilled with an orifice on one or both surfaces, utilizing osmotic pressure for the delivery of drugs. The osmotic tablets have many advantages, such as reducing the risk of adverse reactions and improving patient compliance. Drug release from these systems is independent of $\mathrm{pH}$ and hydrodynamic conditions of the GIT to a large extent, and the release characteristics can be adjusted easily by formulation parameters [910]. The MOT system is simple to be prepared as exempting from push layer and simplifying in the orifice drilling compared with the pushpull osmotic tablet and used in the drug controlled delivery field, especially suitable for water-insoluble drugs [11].

However, solid dispersion is generally for immediate release, as this maximizes the amount of drug absorbed. Sustained release may be obtained by combining solid dispersion technique with MOT so as to increase the therapy efficacy and patient compliance. It is a new concept to combine the solid dispersion technique and osmotic pump technique for water-insoluble drugs in order to obtain much higher solubility and controlled release of water-insoluble drugs at the same time.
In the present study aimed to develop a MOT containing soliddispersions of Ketoprofen (KETO). Ketoprofen [(RS)-2-(3benzoylphenyl) propionic acid is an important nonsteroidal antiinflammatory drug (NSAID), effectively used in the treatment of rheumatoid arthritis, osteoarthritis [12] and musculoskeletal disorders [13]. Because of its short elimination half-life $(4.2 \mathrm{~h})$ which requires multiple dosing to achieve and maintain therapeutic concentration and poor aqueous solubility $\left(0.13 \mathrm{mg} / \mathrm{ml}\right.$ at $\left.25^{\circ} \mathrm{C}\right)$ [14], hazards of adverse gastrointestinal (GI) reactions like gastric irritation, peptic ulceration and bleeding can occur. Development of oral sustained release formulations of this drug is highly desirable in order to achieve improved therapeutic efficacy and patient compliance [15].<smiles>CC(C(=O)O)c1cccc(C(=O)c2ccccc2)c1</smiles>

Fig. 1: Chemical structure of Ketoprofen

The characteristic of the SDs of KETO was studied by in vitro dissolution, DSE, TGA and X-ray diffraction. The influences of formulation variables were also investigated. The optimized MOT of KETO solid dispersion was evaluated for effects of solid dispersion, the ratio of osmotic agent to suspending agent, the amount of plasticizer in the coating, membrane weight gain, and orifice size.

\section{MATERIALS AND METHODS}

\section{Materials}

KETO with a purity of $99.7 \%$ was taken from M/s Ranbaxy Laboratories Ltd. (Gurgaon, India), PEG 6000, sodium chloride ( $\mathrm{NaCl}$ ); polyethylene glycol 1500 (PEG 1500), and cellulose acetate 
(CA) with 39.7 wt \% acetyl content (Mw, 50,000 g/mol) were procured from Thermo Fisher scientific (Mumbai, India); polyethylene oxides (polyox WSR N-80; Mw appro. 200,000) was procured from Colorcon (Goa, India). All other chemicals were of Analytical reagent grade and used without further purification.

\section{Methodology}

\section{Preparation of solid dispersion (SD)}

The solid dispersions of KETO with PEG 6000 were prepared by the solvent melt method [16] in drug: carrier at 1:1, 1:3 and 1:5 (\%w/w) ratio. A sufficient amount of ethanol was used to dissolve KETO. The melted PEG 6000 was added into the KETO solution under stirring at $70{ }^{\circ} \mathrm{C}$ to maintain better dispersion of the drug and to evaporate the small amount of ethanol that was used as the solvent. The melt mass was solidified immediately in a freezing mixture of ice and sodium chloride under constant stirring. The mass was pulverized and sifted through 100 ASTM sieve and stored in a desiccator over fused calcium chloride for $24 \mathrm{~h}$.

\section{Preparation of physical mixtures (PM)}

Physical mixtures (PM) of KETO and PEG 6000 were prepared at 1:1, $1: 3$, and $1: 5(\% \mathrm{w} / \mathrm{w})$ ratio by shifting the individual powders through a 60 ASTM sieve and mixing together by trituration in a mortar with a pestle. The mixture was stored in a desiccator containing calcium chloride for further use.

\section{Characterization of physical mixtures (PM) and solid dispersion (SD)}

\section{Differential scanning calorimetry (DSC)}

DSC thermograms were recorded on a differential scanning calorimeter (Perkin Elmer DSC Pyris 1). Samples were heated at a scanning rate of $10^{\circ} \mathrm{C} / \mathrm{min}$.

\section{Thermogravimetric analysis (TGA)}

TGA (Perkin-Elmer TGA-7 Pyris 1) was performed to evaluate the thermostability of the KETO for the suitability of SD preparation by solvent melt method.

\section{Powder X-ray diffraction (PXRD)}

The scanning PXRD patterns of pure drug (KETO), carrier (PEG 6000 ) and their SDs with corresponding PMs were obtained on an Xray diffractometer (X'PERT-PRO) under the following conditions:

$\mathrm{Ni}$-filtered $\mathrm{Cu}-\mathrm{K} \alpha$ radiation; $45 \mathrm{kV}$ voltage: $40 \mathrm{~mA}$ current, scan speed $2 \%$ min in terms of $2 \theta$ angle.

These PXRD were used to characterize the physical state of the drug in the SDs and PMs. Samples were scanned over a range of $2 \theta$ values from 5 to $50^{\circ}$, at a scan rate of $2.0 \% \mathrm{~min}$.

\section{Preparation of MOT}

The powder sample of KETO solid dispersion was mixed with other excipients (all 40-ASTM sieved) to prepare granules by using water and wet granulation method. The resulting wet granules were dried at $60{ }^{\circ} \mathrm{C}$ for $1 \mathrm{~h}$ and after that, these dried granules were passed through 30 ASTM sieve. The final granules were blended with magnesium stearate and Talc (sieved through \# 60 ASTM) for 10 min. The lubricated powder was compressed into tablets having an average weight of $1000 \mathrm{mg}$ using a 16 station rotary tablet compression machine (Cadmach Ahmedabad, India) fitted with 12 $\mathrm{mm}$ round standard concave punches. The core formulations are listed in table 1.

The core tablets were coated using a coating pan (Ganson Thane, Mumbai) with a diameter of 25 inches. Acetone containing cellulose acetate (CA; $30 \mathrm{~g} / \mathrm{l}, \mathrm{w} / \mathrm{v}$ ) and a certain amount of plasticizer (PEG 1500 ) was used as the coating solution (table 2). Core tablets were placed in the coating pan along with $200 \mathrm{~g}$ dummy tablets (tablets made using 9-mm round deep concave punches, containing microcrystalline cellulose PH 102, lactose DCL 11, and magnesium stearate) with a pan rotating rate of $10 \mathrm{rpm}$. The outlet air temperature was maintained between $20^{\circ} \mathrm{C}$ to $25^{\circ} \mathrm{C}$. The coating solution was sprayed at the rate of 3 to $5 \mathrm{ml} /$ minute until desired weight gain was obtained on the active tablets. All the tablets were dried for $2 \mathrm{~h}$ at $50{ }^{\circ} \mathrm{C}$ and then an orifice was drilled manually by $0.25 \mathrm{~mm}$ drill on one side of the tablets.

Table 1: Quantitative composition of core tablets

\begin{tabular}{|c|c|c|c|c|c|c|}
\hline \multirow[t]{2}{*}{ S. No. } & \multirow[t]{2}{*}{ Ingredients } & \multicolumn{5}{|c|}{ Formulation code ingredients (mg/tablet) } \\
\hline & & T1 & T2 & T3 & T4 & T5 \\
\hline 1 & SD1 & 200 & - & - & - & - \\
\hline 2 & SD2 & - & 400 & - & - & - \\
\hline 3 & SD3 & - & - & 600 & 600 & 600 \\
\hline 4 & Polyox WSR N80 & 140 & 140 & 140 & 185 & 95 \\
\hline 5 & Sodium chloride & 140 & 140 & 140 & 95 & 185 \\
\hline 6 & Microcrystalline cellulose PH102 & q. $s$. & q. $s$. & q. $s$. & q. $s$. & q. $s$. \\
\hline 7 & Magnesium stearate & 10 & 10 & 10 & 10 & 10 \\
\hline 8 & Talc & 10 & 10 & 10 & 10 & 10 \\
\hline \multicolumn{2}{|c|}{ Total weight (mg) } & 1000 & 1000 & 1000 & 1000 & 1000 \\
\hline
\end{tabular}

Table 2: Coating compositions

\begin{tabular}{|c|c|c|c|c|c|}
\hline \multirow[t]{2}{*}{ Ingredients } & \multicolumn{5}{|c|}{ Code/coating compositions (gm) } \\
\hline & C1 & $\mathrm{C} 2$ & C3 & C4 & C5 \\
\hline Cellulose acetate 398-10 & 5.0 & 5.0 & 5.0 & 5.0 & 5.0 \\
\hline PEG 1500 & 0.1 & 0.2 & 0.3 & 0.2 & 0.2 \\
\hline Purified water@10\% w/w & 10 & 10 & 10 & 10 & 10 \\
\hline Acetone ${ }^{@}$ q. s. & 100 & 100 & 100 & 100 & 100 \\
\hline Weight gain $(\% \mathrm{w} / \mathrm{w})$ & 3.0 & 3.0 & 3.0 & 4.0 & 5.0 \\
\hline
\end{tabular}

${ }^{\circledR}$ Evaporates during processing and is not a part of the final product.

\section{In vitro dissolution studies}

In vitro dissolution tests of the pure drug, powdered SDs, PMs and monolithic osmotic tablet (MOT) (equivalent to $100 \mathrm{mg}$ KETO) were performed using the dissolution apparatus (Electrolab, Mumbai, India) type II paddle method at $37 \pm 0.5{ }^{\circ} \mathrm{C}$ for $60 \mathrm{~min}$ for pure drug, powdered SDs, PMs and for MOT $12 \mathrm{~h}$, with a stirring rate of 100 rpm, in $900 \mathrm{ml}$ of a dissolution medium phosphate buffer $\mathrm{pH} 6.8$.
Aliquots of dissolution samples were collected at $0.5,1,2,4,6,8,10$ and $12 \mathrm{~h}$ time interval, with the replacement of an equal volume of temperature-equilibrated dissolution medium. The samples were filtered through a $0.45 \mu \mathrm{m}$ membrane filter, and the concentration of the drug was determined by UV spectrophotometry at $260 \mathrm{~nm}$.

All samples were analyzed in triplicate, and release curves were plotted using calculated mean values of $\%$ cumulative drug release. 
In order to estimate the effects of $\mathrm{pH}$ value of in vitro release mediums and paddle rotation rates on drug release behaviour, release tests were conducted with $\mathrm{pH} 1.2$ buffer and $\mathrm{pH} 6.8$ phosphate buffer at $100 \mathrm{rpm}$, and at a stirring rate of 75, 100 and $125 \mathrm{rpm}$ with $\mathrm{pH} 6.8$ phosphate buffer, respectively. All experiments were also carried out in triplicate.

\section{RESULTS AND DISCUSSION}

\section{Characterization of solid dispersions}

To increase the oral absorption of poorly water-soluble drugs, it is very important to improve the drug solubility and dissolution rate in the GIT. Fig. 2 shows the dissolution profile of KETO in a physical mixture and solid dispersion in comparison with pure KETO powder.

DSC curve of KETO, PEG 6000 and SD in 1:5 ratio shows that the thermogram of KETO exhibited an endothermic peak at about 99.24 ${ }^{\circ} \mathrm{C}$ (fig. 3 a) corresponding to its melting point. The endothermic peak corresponding to melting peak of KETO disappeared in the case of PM and SD with the PEG 6000 (fig. 3 c). The disappearance of drug melting in a lesser amount of drug is due to its dissolution in the melted carrier. Ketoprofen homogenizes with the carriers in an amorphous form
The TGA shows, there is no degradation of KETO was observed up to $160{ }^{\circ} \mathrm{C}$ (M. P. of KETO is $99.24^{\circ} \mathrm{C}$ ) (fig. 4), this confirm that solvent melt method is suitable for KETO solid dispersion preparation.

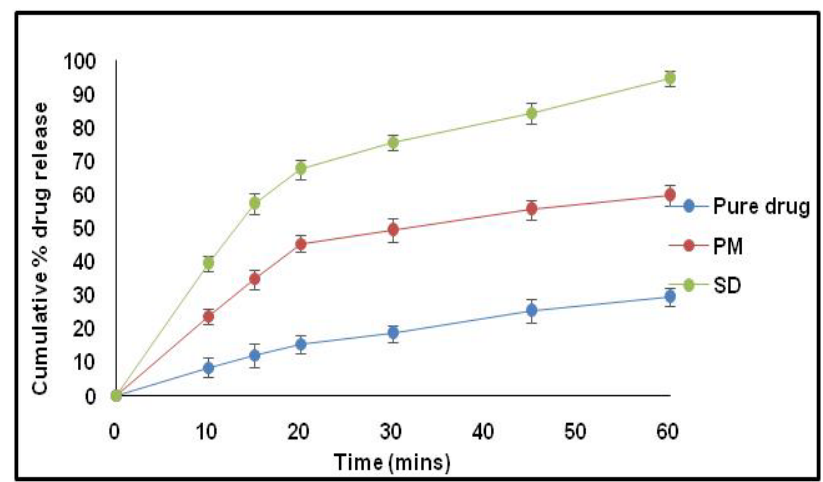

Fig. 2: In vitro dissolution profile of ketoprofen, PM (1:5 ratio), SD (1:5 ratio) in phosphate buffer pH $6.8(n=3)$

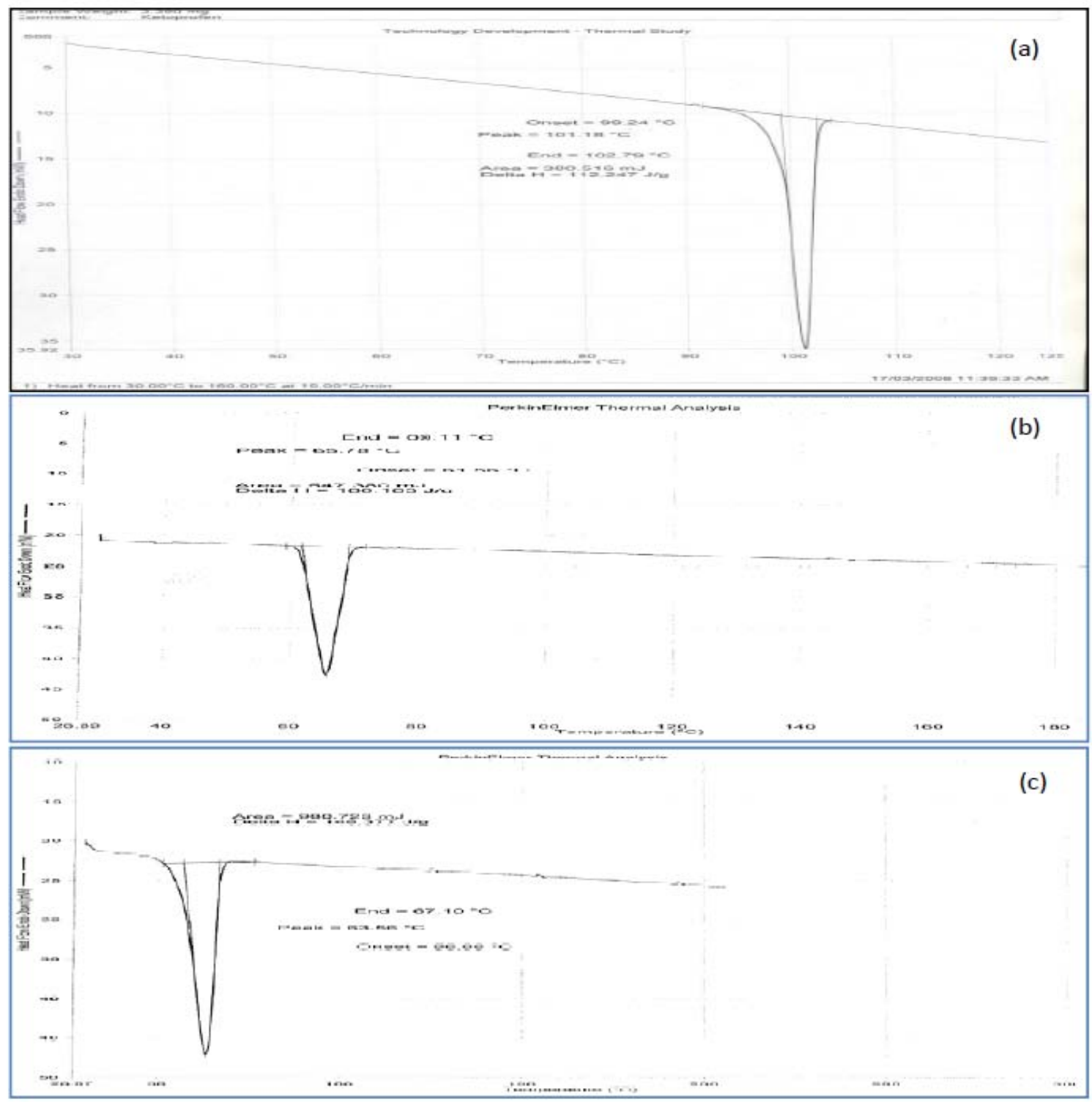

Fig. 3: DSC curve: (a) ketoprofen; (b) PEG6000; (c) ketoprofen and PEG 6000 SD (1:5) 


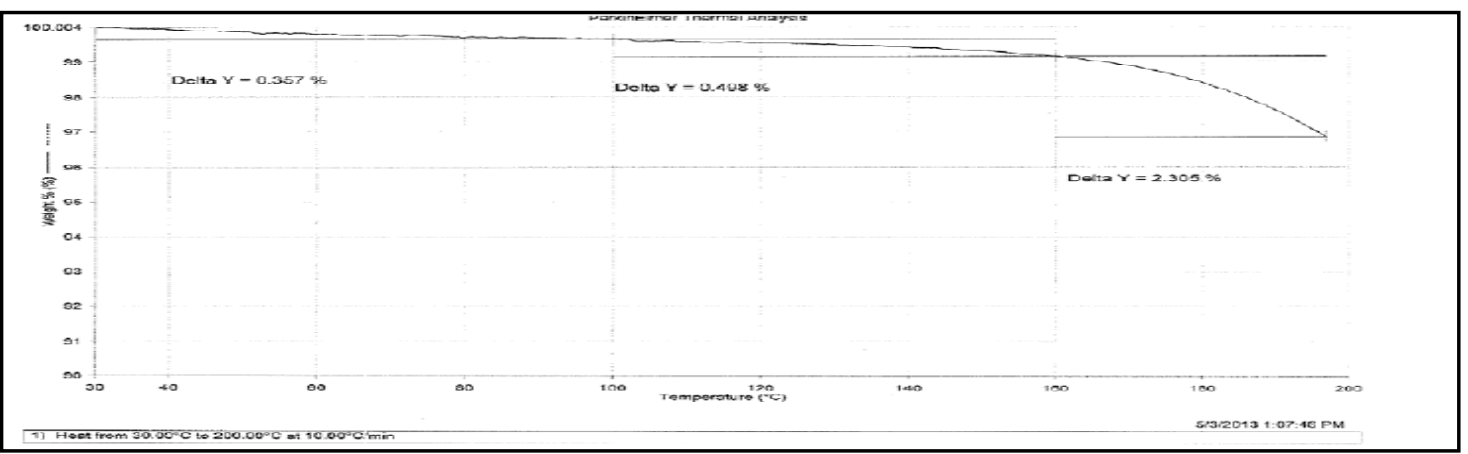

Fig. 4: TGA thermogram of ketoprofen

The dissolution characteristic of KETO physical mixture with PEG 6000 was similar to pure KET, as KETO was still in the crystal form, but far away from the dispersed form in solid dispersion. It was reported that PEG 6000 was able to dissolve more drug in molecularly dispersed form while hindering precipitation of the drug following the dissolution of the carrier [17].

In order to confirm the differences in crystal form between the physical mixture and solid dispersion of KETO, crystal form of the physical mixture and of the solid dispersion were investigated by Xray diffraction (fig. 5). The X-ray diffraction indicated that KETO might be maintained as molecular or amorphous dispersion, which resulted in the enhancement of dissolution. But the drug in the physical mixture did not show much difference in the dissolution profile as it was still in the crystal form [18]. This implied that it was the formation of solid dispersion that enhanced the drug dissolution, not only the solubilization and wetting effects of the physical mixture with PEG 6000.
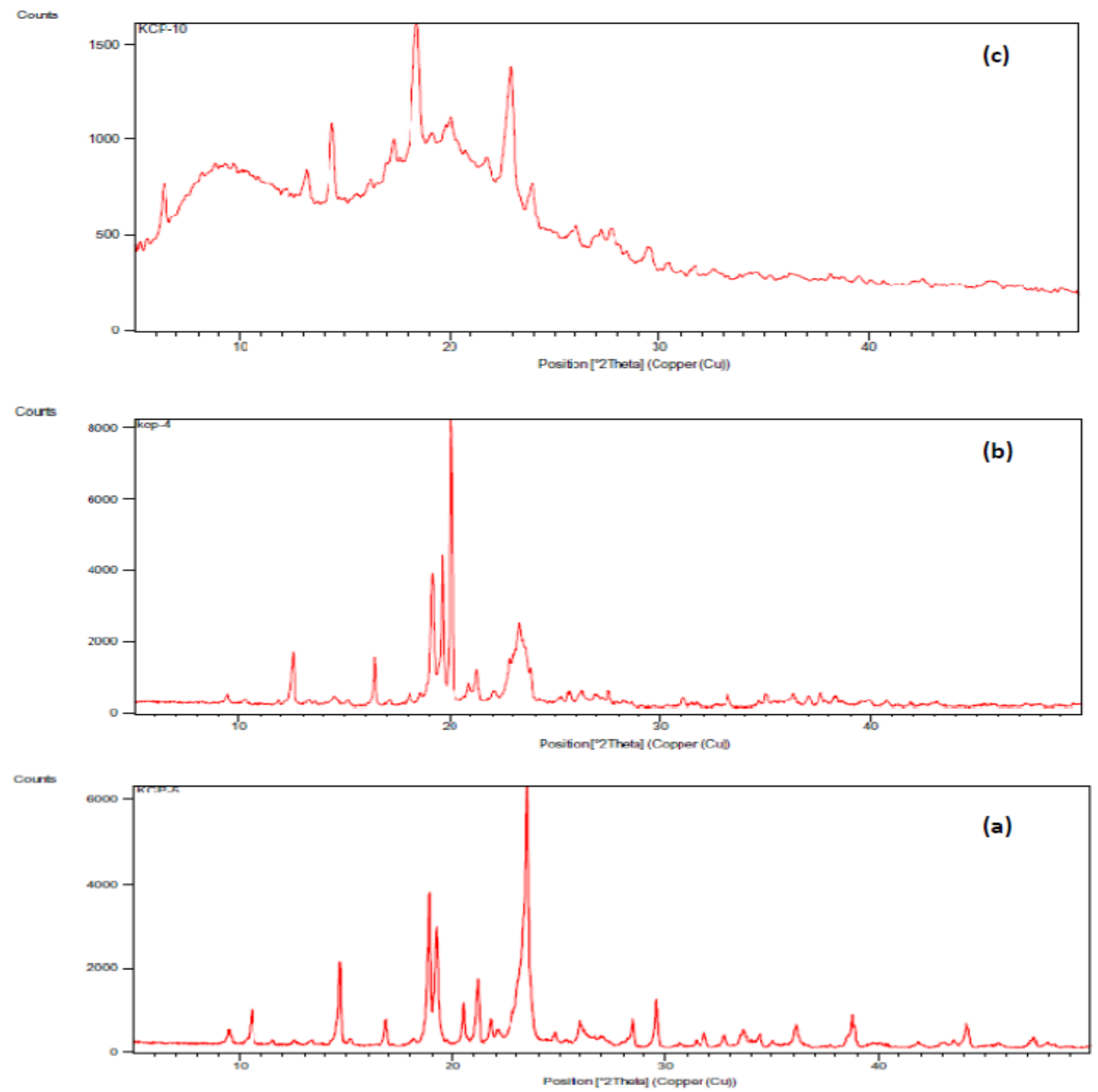

Fig. 5: X-ray diffraction of (a) ketoprofen; (b) ketoprofen and PEG 6000 PM (1:5); (c) Ketoprofen and PEG 6000 SD (1:5) 


\section{Evaluation of monolithic osmotic tablet}

\section{Effects of solid dispersion}

Tablets with a solid dispersion of different formations were prepared and evaluated in vitro release profile. The data in fig. 6 demonstrated that the release profile varied with the change of carrier to drug ratio. The lower release rate was attributed to the drug to carrier ratio at 1:1 because the solubility of KETO was lower, which was crucial in the release of water insoluble drug from the osmotic tablet. The drug may be delivered by the extrusion, either in the form of a suspension of solids in water or, primarily, as a solution, depending on the dissolution dynamic of the core [19]. Also in drug to carrier ratio at 1:3 much bitter release was observed. In the drug carrier ratio at 1:5 constant release was observed up to $12 \mathrm{~h}$.

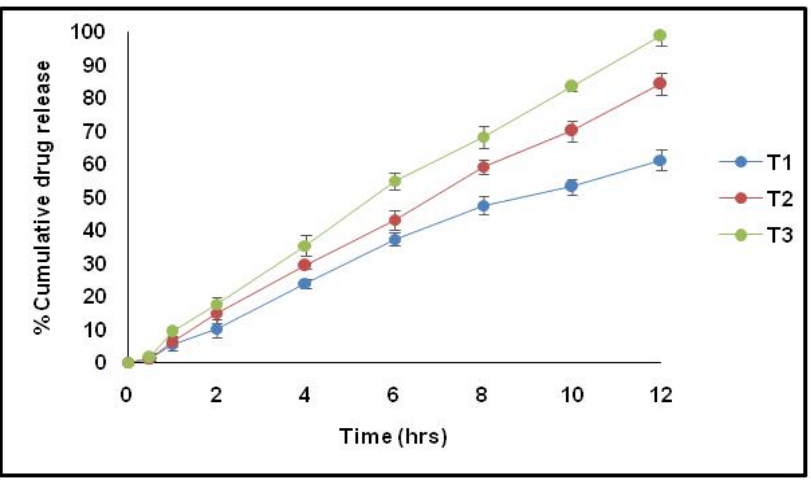

Fig. 6: In vitro drug dissolution profile of MOTs containing different solid dispersions in phosphate buffer pH $6.8(n=3)$

\section{Effects of ratio of osmotic agent to suspending agent}

The ratio of osmotic agent to suspending agent had some influence on the release profile as shown in fig. 7. The more $\mathrm{NaCl}$ incorporated into the tablet, the more components in the core would be dissolved so that the viscosity of the core decreased and thus more drug was released. However, a lower amount of Polyox N80, which played the role of suspending agent, would affect cumulative release. Lower amounts of Polyox N80 led to lower viscosity of the suspension and hardly prevented precipitation of KETO. This was consistent with reported results that osmotic and suspending agents in MOT had a coordinative important effect on the release profile [20]. As a consequence, a moderate $\mathrm{NaCl} /$ Polyox $\mathrm{N} 80$ rate approximate to 1 was selected.

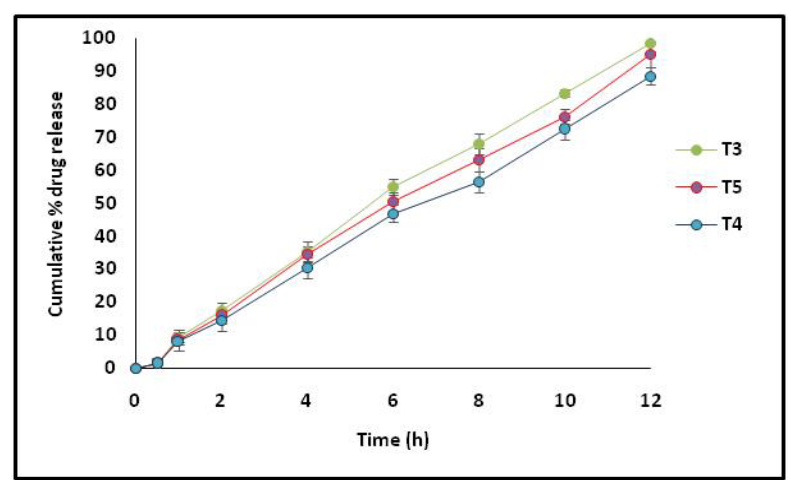

Fig. 7: In vitro drug dissolution profile of MOTs containing different ratio of osmogen to suspending agent in phosphate buffer pH $6.8(n=3)$

\section{Effects of amount of plasticizer}

Besides the formulation of the tablet, the membrane is also a key factor affecting the release profile of the monolithic osmotic tablet
(MOT). As PEG 1500 is a hydrophilic plasticizer, it would be reached easily and left behind a wholly porous structure which increases membrane permeability and drug release rate [21]. The increase of PEG content led to an increase of drug release rate shown in fig. 8. As the amount of PEG 1500 increased into the membrane, the more void space formed and permeability of the membrane increased. Thus, a higher release rate occurred.

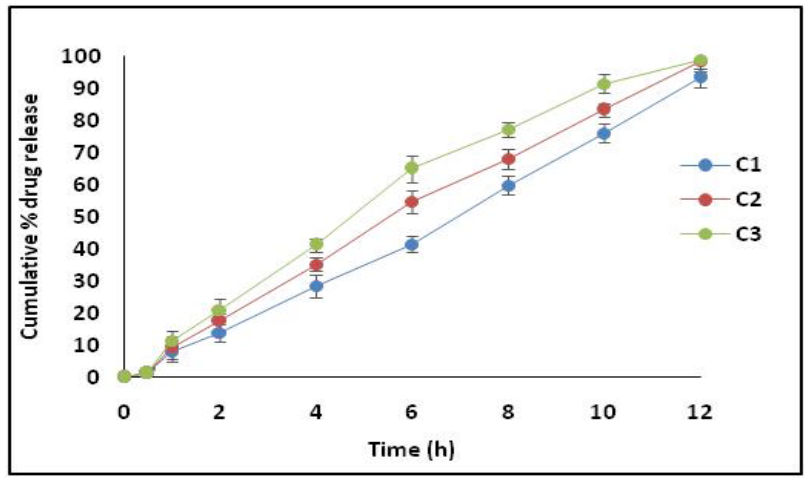

Fig. 8: In vitro drug dissolution profile of MOTs containing different amount of plasticizer in the coating of MOTs in phosphate buffer $\mathrm{pH} 6.8(\mathrm{n}=3)$

\section{Effects of membrane weight gain}

To study the effects of membrane thickness on the drug release, tablets were coated with different weight gain. Fig. 9 shows that drug release decreased with the increased of the weight gain of the membrane. As the weight gain increased, the resistance of the membrane to water diffusion increased, and the rate of imbibing water decreased. As a consequence, the drug release rate was reciprocal to the weight gain. It was found that coating formulation C2 together with optimal tablet formulation T3 could attain approximate zero-order release pattern.

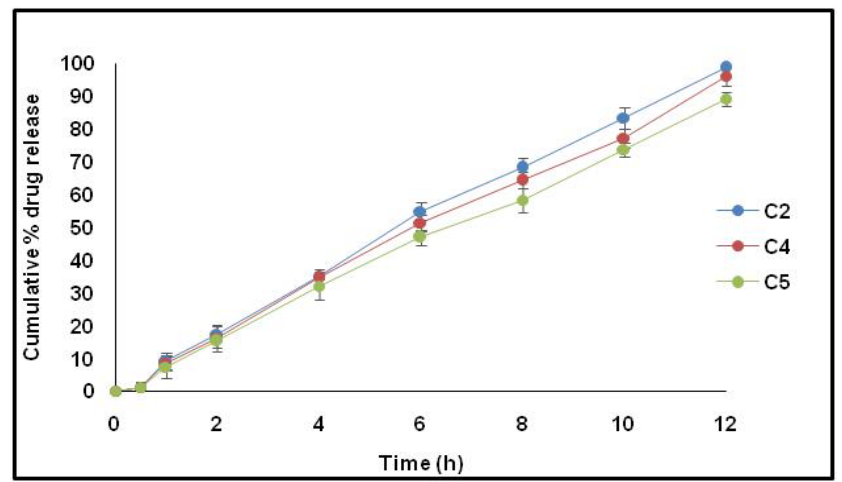

Fig. 9: In vitro drug dissolution profile of MOTs containing different coating membrane weight gain in phosphate buffer $\mathrm{pH} 6.8(\mathrm{n}=3)$

\section{Effects of orifice size}

It was reported that orifice sizes should be kept in an appropriate range so as to maintain zero-order release. Orifice sizes must be smaller than the maximum limit, to avoid diffusion delivery through the orifice, and larger than the minimum limit, to minimize hydrostatic pressure inside the system [22]. The tablet core T3 was coated with formulation C2 and was subsequently drilled with a circular orifice of the same diameter on each side of the surface. Fig. 11 shows the effects of orifice size on release profile.

Orifice sizes between $200 \mu \mathrm{m}$ to $300 \mu \mathrm{m}$ could maintain steady release and high cumulative release percentage, while an orifice size 
of $100 \mu \mathrm{m}$ resulted in lower release rate as drug suspension may occlude such a small orifice, therefore leading to a low release rate. An orifice diameter of $200 \mu \mathrm{m}$ to $300 \mu \mathrm{m}$ contributed to a similar release profile as it was within the optimal range. The orifice size was measured with stage micrometer and microscope. The MOT orifice is shown in fig. 10.
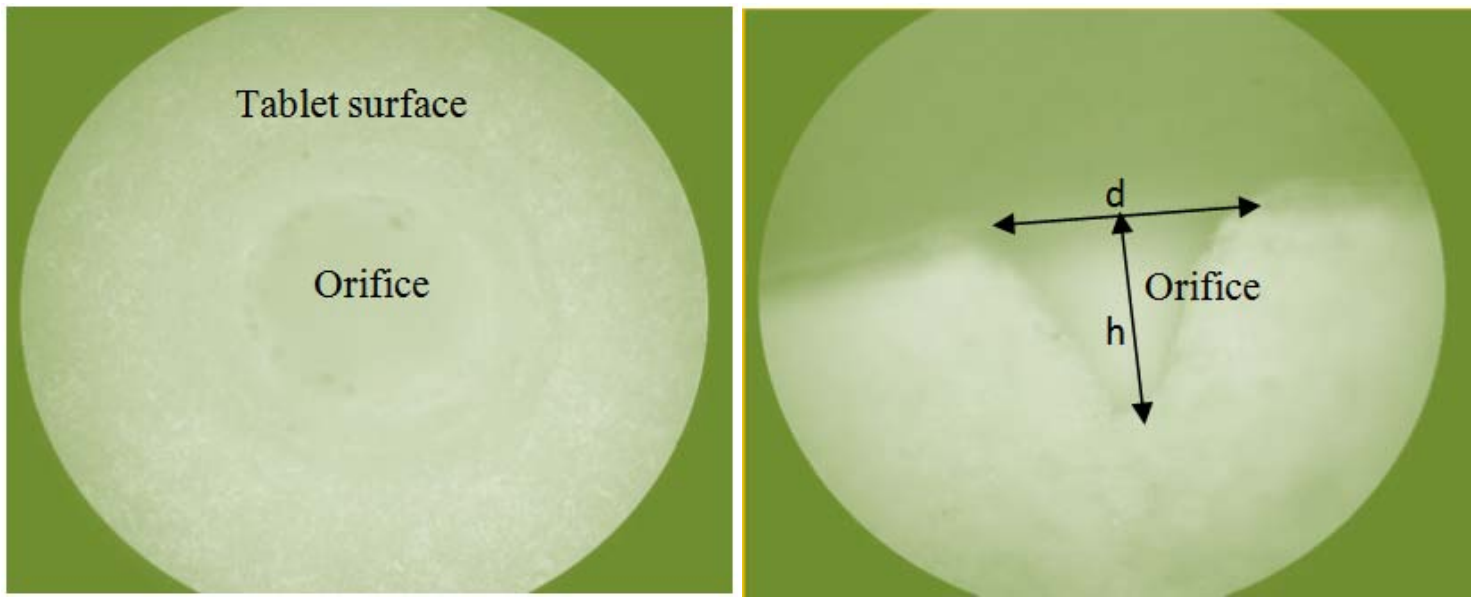

Fig. 10: MOT; Upper surface view, MOT; Vertical cross section view

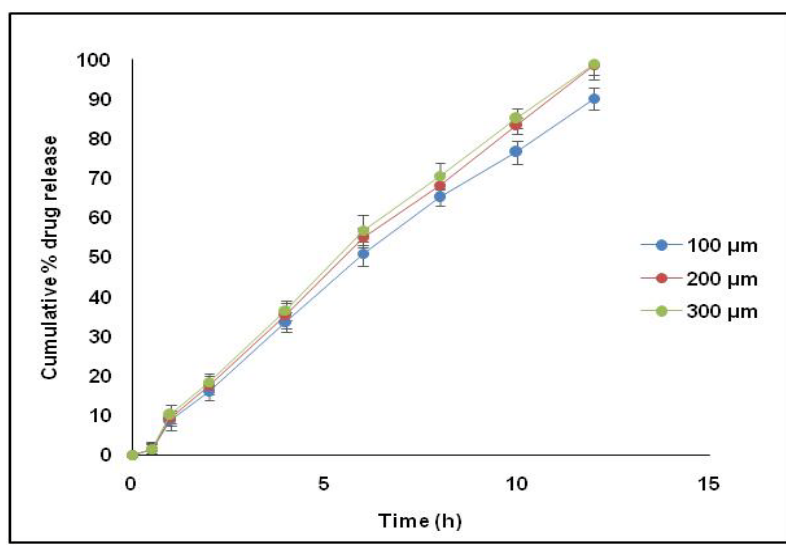

Fig. 11: In vitro drug dissolution profile of MOTs containing different orifice size in phosphate buffer $\mathrm{pH} 6.8(\mathrm{n}=3)$

\section{Evaluation of the optimized formulation}

To investigate the influence of release media on drug release, in vitro releases were tested in $\mathrm{pH} 1.2$ buffers and $\mathrm{pH} 6.8$ phosphate buffer at $100 \mathrm{rpm}$. Optimized formulation exhibits a linear release pattern up to $12 \mathrm{~h}$, and no significant difference in release profile could be found in different release media $(p>0.05)$. Therefore, it may be expected that the drug release from MOT in the GI fluid exhibited a media-independent characteristic. The influences of stirring rate on drug release profile (at 75, 100, and $125 \mathrm{rpm}$ ) were also examined, respectively. Increasing agitation rate did not influence the release profile significantly $(\mathrm{p}>0.05)$. Thus the mobility of the GIT may scarcely affect the drug release of the MOT. Drug release was independent on release media and agitation rate, and the monolithic osmotic tablet was reported to exhibit a comparable in vitro/in vivo release profile [21].

As for the water-insoluble drug, the solubility would be too low to form a homogeneous drug suspension and affect drug dissolution. Thus, solid dispersion formation was applied so as to enhance the solubility and the dissolution rate. $\mathrm{NaCl}$ as the osmotic agent played an indispensable role because the osmotic mechanism was the main energy source to imbibe water and the basis of all osmotic delivery systems. In addition, carrier PEG 6000 also has the osmotic effect to some extent [23]. Meanwhile, suspending agent polyox N80 was applied to increase the viscosity, stabilize the suspension, and swelling. In operation, water was imbibed owing to the osmotic pressure difference between the inside of the tablet membrane and the outside environment, which was contributed by $\mathrm{NaCl}$. Then KET in solid dispersion form dissolved, and a viscous KETO suspension was created as polyox imbibed water and swelled. The solid dispersion facilitated rapid dissolution and higher drug concentration within the tablet, and the drug suspension was pumped out through the orifices. The drug release was controlled by osmotic and suspension mechanisms, while the solid dispersion form was utilized to increase drug solubility, dissolution rate, and dispersion degree. It was reported that Poiseuille's law of laminar flow could be applied to describe drug release in MOT [24] as in Equation 1:

$$
\frac{\mathrm{dM}}{\mathrm{dt}}=\frac{\pi \mathrm{Cr}^{4} \mathrm{P}_{1}-\mathrm{P}_{2}}{8 \eta \mathrm{h}} \ldots \ldots . . . \text { Eq. } 1
$$

Where:

$\mathrm{dM} / \mathrm{dt}=$ drug release rate,

$\mathrm{C}=$ concentration of drug in tablet suspension,

$r=$ radius of the orifice,

$\eta=$ viscosity of tablet suspension,

$\left(\mathrm{P}_{1}-\mathrm{P}_{2}\right)=$ pressure difference between the inside and outside of the membrane

$\mathrm{h}=$ thickness of the membrane.

In this MOT containing KETO in solid dispersion form, C is largely dependent on the solubility of KETO in solid dispersion and dispersed degree in tablet core. Solid dispersion helped to improve drug dissolution rate and maintain a high and constant drug concentration in the core. This is because the drug in solid dispersion is in supersaturation form. $\left(\mathrm{P}_{1}-\mathrm{P}_{2}\right)$ represents both osmotic pressure and swelling effect, and it was that force driving the drug release. The drug release rate is inversely proportional to $\eta$ and. If $\eta$ value is too high, the release rate will be decreased, as a swelling effect could not maintain well-proportioned suspension; if $\eta$ value is too low, the solid drug dispersion may precipitate and be unable to maintain $\mathrm{C}$ high enough for constant release. In summary, drug release from MOT containing solid dispersion can be contributed to the osmotic, suspending, and solubility enhancement.

\section{CONCLUSION}

MOT containing a solid dispersion of KETO were prepared. Solid dispersion consisted of PEG 6000 and KETO could enhance the solubility, dissolution rate of water-insoluble drug KETO. Drug release was investigated in vitro. The optimal MOT was able to 
deliver KETO at a constant rate of $6.25 \mathrm{mg} /$ hour for up to $12 \mathrm{~h}$ in phosphate buffer $\mathrm{pH} 6.8$, and cumulative release at $12 \mathrm{~h}$ is above $95 \%$, independent of environment media and stirring rate. The release is controlled by osmotic and suspending effect while integrating solid dispersion for solubility enhancement. MOT was simple to prepare and there is no need to differentiate the orifice drill surface. The MOT containing solid dispersion has great potential in the controlled delivery of water insoluble drugs.

\section{ACKNOWLEDGEMENT}

The authors would like to colorcon for supplying free gift sample of polyethylene oxides.

\section{CONFLICT OF INTERESTS}

Declared none

\section{REFERENCES}

1. Yogesh R, Rajshree M, Mayur S, Jolly S. Effect of swellable hydrophilic polymers on dissolution enhancement of carbamazepine solid dispersions studied using response surface methodology. AAPS PharmSciTech 2007;8:E1-E11.

2. Sun Y, Yang R, Zhou W, Tang X. Nimodipine semi-solid capsules containing solid dispersion for improving dissolution. Int J Pharm 2008;359:144-9.

3. Chaud MV, Tamascia P, Lima AC, Paganelli MO, Gremião MPD, Freitas 0 . Solid dispersions with hydrogenated castor oil increase solubility, dissolution rate and intestinal absorption of praziquantel. Brazilian J Pharm Sci 2010;46:473-81.

4. Correa EM, Vila MMDC, Junior JMO, Zaparoli RE, Granato MM, Goes AL, et al. Assessment of solubility and intestinal absorption in vitro of praziquantel in solid dispersions of polyethylene glycol 6000. J Latin Am Pharm Sci 2011;30:1910-5.

5. Sharma A, Jain CP. Preparation and characterization of a solid dispersion of carvedilol with PVP K30. Res Pharm Sci 2010;5:49-56

6. Shirke SH, Shewale SB, Kulkarni AS, Aloorkar NH. Solid dispersion: a novel approach for poorly water soluble drugs. Int J Curr Pharm Res 2015;7:1-8.

7. Urbanetz NA, Lippold BC. Solid dispersions of nimodipine and polyethylene glycol 2000: dissolution properties and physicochemical characterization. Eur J Pharm 2005;59:107-18.

8. Patel PM, Patel RM, Patel HNl, Gajjar DG. Enhanced solubility of non-steroidal anti-inflammatory drugs by hydroxyl terminated striazine-based dendrimers. Asian J Pharm Clin Res 2014;7:156-61.

9. Verma RK, Mishra B, Garg S. Osmotically controlled oral drug delivery. Drug Dev Ind Pharm 2000;26:695-708.

10. Verma RK, Krishna DM, Garg S. Formulation aspects in the development of osmotically controlled oral drug delivery systems. J Controlled Release 2002;79:7-27.
11. Malaterre V, Ogorka J, Loggia N, Gurny R. Oral osmotically driven systems: 30 y of development and clinical use. Eur J Pharm Biopharm 2009;73:311-23.

12. Joseph DT, Robert TL, Gary YC, Gary MR, Barbara WG, Michael PL. Pharmacotherapy: a pathophysiologic approach. $5^{\text {th }}$ ed. New York: McGraw-Hill; 1993.

13. Tripathi KD. Essentials of medical pharmacology. $5^{\text {th }}$ ed. New Delhi: Jaypee Brothers; 2003.

14. Zhang RW, Li YF, Cai QY, Liu TP, Sun H. Preclinical pharmacology of the natural product anticancer agent Ketoprofen,an inhibitor of topoisomerase I. Cancer Chemother Pharmacol 1998;41:257-67.

15. Mauludin R, Pamudji SJ, Buy anti-D. Dissolution improvement of ketoprofen tablets by solid dispersion method. Asian J Pharm Clin Res 2011;4:119-24.

16. Liu C, Wu J, Shi B, Zhang Y, Gao T, Pei Y. Enhancing the bioavailability of cyclosporine a using solid dispersion containing polyoxyethylene stearate. Drug Dev Ind Pharm 2006;32:115-23.

17. Leuner C, Dressman J. Improving drug solubility for oral delivery using solid dispersions. Eur J Pharm 2000;50:47-60.

18. Craig DQM. The mechanisms of drug release from solid dispersions in water-soluble polymers. Int J Pharm 2002;231:131-44.

19. Appel LE, Curatolo WJ, Herbig SM, Nightingale JAS, Thombre AG. The osmotic system for delivery of amorphous solid dispersions of drugs. Eur Patent; 2000.

20. Liu L, Khang G, Rhee JM, Lee HB. Monolithic osmotic tablet system for Nifedipine delivery. J Controlled Release 2000;67:309-22.

21. Lu EX, Jiang ZQ, Zhang QZ, Jiang XG. A water-insoluble drug monolithic osmotic tablet system is utilizing gum Arabic as an osmotic, suspending and expanding agent. J Controlled Release 2003;92:375-82.

22. Theeuwes F, Higuchi T. Osmotic dispensing device with maximum and minimum sizes for the passageway. U. S. Patent: 1975.

23. Ke D, Sun G. The effect of reactive oxygen species on ethylene production induced by osmotic stress in etiolated mung bean seedling. Plant Growth Regul 2004;44:149-55.

24. Lu EX, Jiang ZQ, Zhang QZ, Jiang XG. A water-insoluble drug monolithic osmotic tablet system is utilizing gum Arabic as an osmotic, suspending and expanding agent. J Controlled Release 2003;92:375-82.

\section{How to cite this article}

- S Kaushik, Kamla Pathak. Development and evaluation of monolithic osmotic tablet of ketoprofen: using solid dispersion technique. Int J Pharm Pharm Sci 2016;8(12):41-47. 